\title{
THERMAL CHARACTERIZATION OF THE In-Sn-Zn EUTECTIC ALLOY
}

\author{
Dragan Manasijevićl ${ }^{*}$, Ljubiša Balanovićl, ${ }^{2}$ Vladan Ćosović ${ }^{2}$, Duško Minić ${ }^{3}$, \\ Milena Premović ${ }^{3}$, Milan Gorgievski ${ }^{1}$, Uroš Stamenković ${ }^{1}$, Nadežda Talijan ${ }^{4}$ \\ ${ }^{1}$ University of Belgrade, Technical Faculty in Bor, Bor, Serbia \\ ${ }^{2}$ University of Belgrade, Institute of Chemistry, Technology and Metallurgy, Belgrade, \\ Serbia \\ ${ }^{3}$ University of Priština, Faculty of Technical Sciences, Kosovska Mitrovica, Serbia \\ ${ }^{4}$ Academy of Engineering Sciences of Serbia, Department of Technology, Metallurgy \\ and Materials Science, Belgrade, Serbia
}

Received 04.12.2019

Accepted 17.12.2019

\begin{abstract}
Thermal properties, including melting temperature, latent heat of melting, specific heat capacity and thermal conductivity, of a low-melting In-Sn-Zn eutectic alloy were investigated in this work. The In-Sn-Zn eutectic alloy with nominal composition 52.7In$44.9 \mathrm{Sn}-2.4 \mathrm{Zn}$ (at.\%) was prepared by the melting of pure metals under an argon atmosphere. The conducted assessment consisted of both theoretical and experimental approaches. Differential scanning calorimetry (DSC) was used for the measurement of melting temperature and latent heat, and the obtained results were compared with the results of thermodynamic calculations. The measured melting temperature and the latent heat of melting for the $\mathrm{In}-\mathrm{Sn}-\mathrm{Zn}$ eutectic alloy are $106.5 \pm 0.1{ }^{\circ} \mathrm{C}$ and $28.3 \pm 0.1 \mathrm{Jg}^{-1}$, respectively. Thermal diffusivity and thermal conductivity of the In-Sn-Zn eutectic alloy were studied by the xenon-flash method. The determined thermal conductivity of the investigated eutectic alloy at $25^{\circ} \mathrm{C}$ is $42.2 \pm 3.4 \mathrm{Wm}^{-1} \mathrm{~K}^{-1}$. Apart from providing insight into the possibility for application of the investigated alloy as the metallic phase-change material, the obtained values of thermal properties can also be utilized as input parameters for various simulation processes such as casting and soldering.
\end{abstract}

Keywords: In-Sn-Zn system; eutectic alloy; latent heat of melting; thermal conductivity.

\footnotetext{
*Corresponding author: Dragan Manasijević,dmanasijevic@tfbor.bg.ac.rs
} 


\section{Introduction}

Alloys based on the low-melting metals $\mathrm{Sn}, \mathrm{Zn}$, and In have been extensively studied and commercially used in the field of lead-free soldering [1]. Among many potential substitutes for the $40 \mathrm{~Pb}-60 \mathrm{Sn}$ solder alloy, Sn-rich ternary Sn-Zn-In alloys were considered as very suitable candidates [2]. MacCormack et al. [3] developed a new Sn$\mathrm{Zn}$-In solder alloy and revealed that addition of In into the $\mathrm{Sn}-\mathrm{Zn}$ alloys could positively contribute to their wetting characteristics and lower their melting temperatures appropriately.

Based on the previously published experimental studies [3-5], Cui et al. [2] performed thermodynamic modeling and calculated thermodynamically optimized phase diagram of the ternary In-Sn-Zn system. Because of their practical importance in leadfree soldering, previous experimental investigations of the $\mathrm{In}-\mathrm{Sn}-\mathrm{Zn}$ alloys were mainly focused on the Sn-rich alloys [3]. However, obtained results from [2] pointed out to the existence of one ternary eutectic reaction in the In-Sn-Zn system with the eutectic temperature of $106{ }^{\circ} \mathrm{C}$ and eutectic composition 52.7In-44.9Sn-2.4Zn (at.\%). This eutectic composition corresponds to the alloy with the lowest melting temperature in the ternary In-Sn-Zn system, which could be relevant for the development of metallic phase change materials (PCMs) [6-12].

Thermophysical property data for pure metals and many lead-free solders such as $\mathrm{Sn}-\mathrm{Pb}, \mathrm{Sn}-\mathrm{Bi}, \mathrm{Sn}-\mathrm{Zn}, \mathrm{Sn}-\mathrm{Ag}$, and $\mathrm{Sn}-\mathrm{Ag}-\mathrm{Cu}$ alloys are available in the literature [13-15]. Also, recently, the thermal properties of the eutectic alloys from the Bi-In binary system and the Bi-In-Sn ternary system have been investigated by Manasijević et al. [11,12]. However, such data is still not available for many multicomponent low-melting eutectic alloys with potential usage in the field of thermal energy storage [9-12]. One of these lowmelting alloys is the In-Sn-Zn eutectic alloy which is the research subject of this study.

The focus of this work is put on the thermodynamic assessment and experimental investigation of thermal properties, including melting temperature, latent heat of fusion, and thermal conductivity of the eutectic alloy from the In-Sn-Zn ternary system. The validity of the carried out thermodynamic calculations was estimated by mutual comparison of the obtained results and experimental results.

\section{Experimental}

Studied In-Sn-Zn eutectic alloy with overall composition 52.7In-44.9Sn-2.4Zn (at.\%) was prepared by induction melting of pure elements (In $99.995 \%, \mathrm{Sn} 99.99 \%, \mathrm{Zn}$ 99.99\%, Alfa Aesar) in a graphite crucible under an argon atmosphere. The mass of the prepared sample was about $3 \mathrm{~g}$. The overall composition and microstructural homogeneity of the prepared alloy were checked by SEM-EDS analysis. Melting temperature and latent heat of melting of the eutectic In-Sn-Zn alloy were measured by using simultaneous thermal analyzer SDT Q600 (TA Instruments). Applied experimental parameters were: sample's mass $(50 \mathrm{mg})$, heating rate $\left(5^{\circ} \mathrm{Cmin}^{-1}\right)$ and reference material (empty alumina crucible).

Discovery Xenon Flash DXF-500 (TA Instruments) apparatus was used for thermal diffusivity measurements. For that purpose, the sample of the investigated In$\mathrm{Sn}-\mathrm{Zn}$ eutectic alloy was shaped into a round disk ( $12.6 \mathrm{~mm}$ in diameter and $2 \mathrm{~mm}$ thick) by hydraulic pressing. After shaping the sample was annealed at $80{ }^{\circ} \mathrm{C}$ under an inert atmosphere for $5 \mathrm{~h}$ and slowly cooled to room temperature. The subsequent thermal 
diffusivity measurement was carried out at $25{ }^{\circ} \mathrm{C}$ under argon atmosphere. A liquid nitrogen-cooled IR detector was used for temperature measurements [16].

\section{Results and discussion}

Thermodynamic analysis

The CALPHAD (Calculation of Phase Diagram) method [17,18] was applied for thermodynamic calculations. Optimized thermodynamic parameters for the ternary In$\mathrm{Sn}-\mathrm{Zn}$ system from Cui et al. [2] included in the COST 531 database [19] and Pandat software [20] were used in the present study.

The calculated liquidus projection of the selected ternary In-Sn-Zn system is presented in Fig. 1. It includes 5 primary crystallization fields of ( $\mathrm{Zn}),(\mathrm{Sn}),(\mathrm{In})$ solid solution phases, In-rich $\beta$ phase, and $S n$-rich $\gamma$ phase. Three ternary invariant reactions appear in the In-Sn-Zn ternary system. Two of them are ternary quasi-peritectic or transition reactions (U-type), and one is a ternary eutectic reaction (E-type).



Fig. 1. Calculated liquidus projection of the In-Sn-Zn ternary system based on the optimized thermodynamic parameters from [2, 19].

The calculated eutectic temperature and the eutectic alloy composition are given in Table 1 .

Table 1. Calculated eutectic temperature and composition of the In-Sn-Zn eutectic alloy using the optimized thermodynamic parameters from $[2,19]$

\begin{tabular}{|c|c|c|c|c|}
\hline \multirow{2}{*}{$\mathrm{T}\left({ }^{\circ} \mathrm{C}\right)$} & \multicolumn{3}{|c|}{ Composition in mole fractions } \\
\cline { 3 - 5 } & Invariant eutectic reaction & $\mathrm{x}(\mathrm{In})$ & $\mathrm{x}(\mathrm{Sn})$ & $\mathrm{x}(\mathrm{Zn})$ \\
\hline 106.0 & Liquid $\rightarrow \beta+\gamma+(\mathrm{Zn})$ & 0.527 & 0.449 & 0.024 \\
\hline
\end{tabular}


By reaching the eutectic temperature $\left(106.0^{\circ} \mathrm{C}\right)$, ternary eutectic reaction Liquid $\rightarrow \beta+\gamma+(\mathrm{Zn})$ occurs, and liquid phase isothermally transforms into the eutectic mixture of In-rich $\beta$ phase, Sn-rich $\gamma$ phase, and (Zn) solid solution phase. Right below the eutectic temperature microstructure of the alloy is composed of a eutectic mixture of $\beta, \gamma$ and $(\mathrm{Zn})$ phases. According to the results of thermodynamic calculation, the In-rich $\beta$ phase has the most significant phase fraction and $(\mathrm{Zn})$ phase has the smallest phase fraction.

Fig. 2 shows the calculated enthalpy vs. temperature dependence for the investigated In-Sn-Zn eutectic alloy. It can be seen that the enthalpy of the investigated In-Sn-Zn eutectic alloy gradually increases with temperature rise. At the eutectic temperature, there is a rapid increase in the enthalpy caused by the eutectic phase transformation. Enthalpy of melting $\left(\Delta \mathrm{H}_{\mathrm{m}}\right)$ or latent heat of melting represents enthalpy change during the melting of the alloy, and it is equivalent to the enthalpy difference between the liquid and solid-state of the alloy at the melting temperature. According to the obtained results, the calculated latent heat of melting for the $\mathrm{In}-\mathrm{Sn}-\mathrm{Zn}$ eutectic alloy is $2486 \mathrm{Jmol}^{-1}\left(21.5 \mathrm{Jg}^{-1}\right)$. This calculated value is compared with the results of DSC measurements in the latter part of the study.



Fig. 2. Temperature dependence of enthalpy for the In-Sn-Zn eutectic alloy.

The calculated dependence of specific heat capacity on temperature for the eutectic In-Sn-Zn alloy is given in Fig. 3. Similar to the enthalpy, there is a gradual increase in the specific heat capacity of the investigated alloy with temperature increase. At the eutectic temperature, there is a sharp drop in the specific heat capacity caused by alloy melting. The calculated value of specific heat capacity at $25^{\circ} \mathrm{C}\left(0.233 \mathrm{Jg}^{-1} \mathrm{~K}^{-1}\right)$ was used for the determination of thermal conductivity for the In-Sn-Zn eutectic alloy. To check the precision of the specific heat capacity calculation results, they were compared with experimentally determined values reported by Wu et al. [14]. In the mentioned study [14], the authors have investigated specific heat capacities of $\mathrm{Sn}-\mathrm{Zn}$ and $\mathrm{Sn}-\mathrm{Ag}-\mathrm{Cu}$ solder 
alloys using the DSC method and reported value of $0.252 \mathrm{Jg}^{-1} \mathrm{~K}^{-1}$ at $30{ }^{\circ} \mathrm{C}$ for the $\mathrm{Sn}-9 \mathrm{Zn}$ (wt.\%) solder alloy. This value is in reasonable agreement with the corresponding calculated specific heat capacity value $\left(0.245 \mathrm{Jg}^{-1} \mathrm{~K}^{-1}\right)$ from the current study obtained using the optimized thermodynamic dataset. Based on the conducted comparison of the results, it can be concluded that the calculated specific heat capacity values from this work are to a large extent, supported by the existing experimentally obtained data.

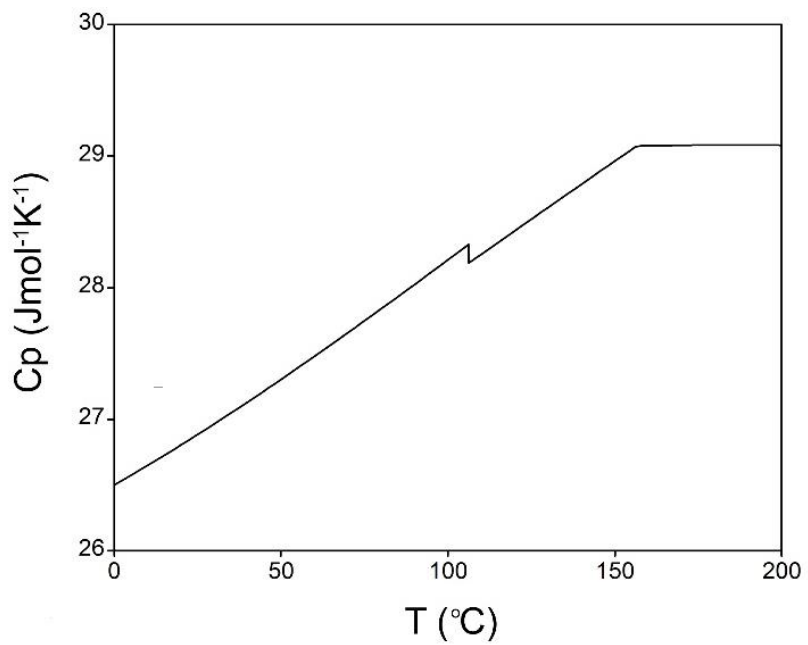

Fig. 3. Calculated dependence of specific heat capacity on temperature

for the In-Sn-Zn eutectic alloy

Measurements of melting temperature and latent heat of melting

Melting temperature and latent heat of melting represent thermal properties of crucial importance for the design and selection of PCMs. For the majority of low-melting metals and alloys, values of latent heat of melting are generally low (lower than $100 \mathrm{Jg}^{-1}$ ), which represents their severe drawback compared with other kinds of PCMs. In this work, melting (eutectic) temperature and latent heat of melting of the investigated In-Sn-Zn eutectic alloy were studied using the DSC technique. The determination of the melting temperature was done based on the extrapolated temperature of the DSC peak onset $[11,12,21]$. DSC heating runs were repeated five times and average values of the melting temperature and latent heat were calculated using the obtained results of the repeated tests.

An example of a DSC heating curve for the investigated In-Sn-Zn eutectic alloy is given in Fig.4. 


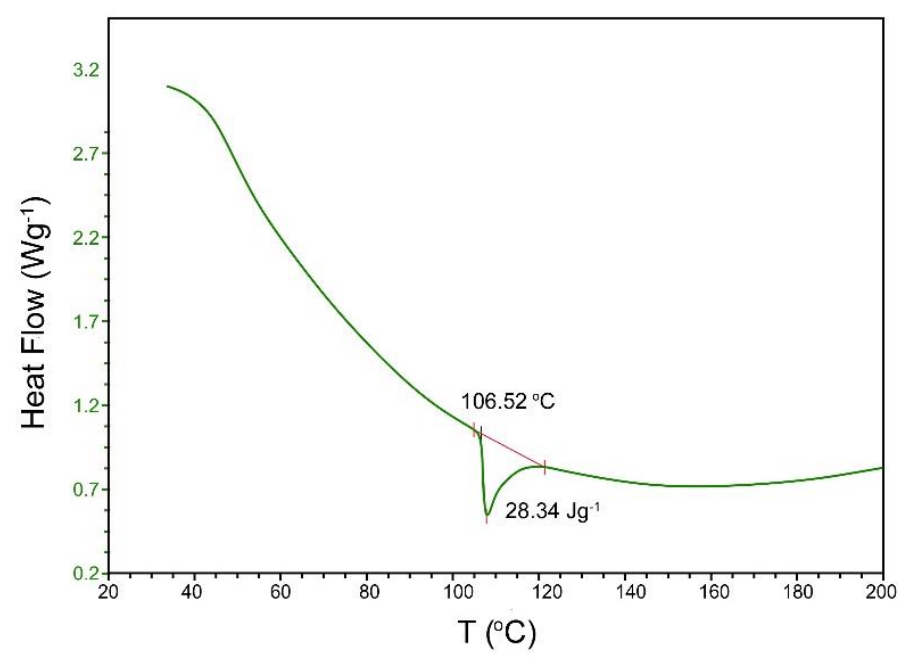

Fig. 4. DSC heating curve for the investigated In-Sn-Zn eutectic alloy

Table 2 presents a comparison between the experimental results and the results of a thermodynamic calculation. The average value of eutectic temperature and latent heat of melting together with standard uncertainties evaluated from the five repeated tests are presented in Table 2.

Table 2. Results of thermodynamic calculation and DSC measurements for the In-Sn-Zn eutectic alloy.

\begin{tabular}{|c|c|c|c|}
\hline \multicolumn{2}{|c|}{ Calculation } & \multicolumn{2}{c|}{ DSC results } \\
\hline $\begin{array}{c}\text { Eutectic } \\
\text { temperature } \\
\left({ }^{\circ} \mathrm{C}\right)\end{array}$ & $\begin{array}{c}\text { Latent heat of } \\
\text { melting } \\
\left(\mathrm{Jg}^{-1}\right)\end{array}$ & $\begin{array}{c}\text { Eutectic } \\
\text { temperature } \\
\left({ }^{\circ} \mathrm{C}\right)\end{array}$ & $\begin{array}{c}\text { Latent heat of } \\
\text { melting } \\
\left(\mathrm{Jg}^{-1}\right)\end{array}$ \\
\hline 106.0 & 21.5 & $106.5 \pm 0.1$ & $28.3 \pm 0.1$ \\
\hline
\end{tabular}

The experimentally determined melting temperature and the latent heat of melting for the In-Sn-Zn eutectic alloy $\left(106.5{ }^{\circ} \mathrm{C}\right.$ and $28.3 \mathrm{Jg}^{-1}$, respectively) are somewhat higher than the corresponding calculated values $\left(106.0{ }^{\circ} \mathrm{C}\right.$ and $\left.21.5 \mathrm{Jg}^{-1}\right)$. The experimentally obtained latent heat of melting for the $\mathrm{In}-\mathrm{Sn}-\mathrm{Zn}$ eutectic alloy is somewhat lower than the corresponding value for the binary $\mathrm{Sn}-\mathrm{Zn}$ alloy $\left(32.5 \mathrm{Jg}^{-1}\right)$ published in [9]. Values of melting temperature and latent heat of melting for two ternary

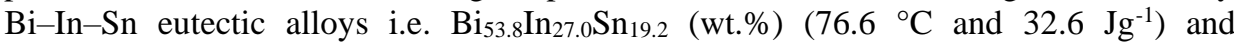
$\mathrm{Bi}_{32.0} \mathrm{In}_{51.2} \mathrm{Sn}_{16.8}$ (wt.\%) $\left(60.8{ }^{\circ} \mathrm{C}\right.$ and $\left.25.4 \mathrm{Jg}^{-1}\right)$ have been recently reported by Manasijević et al. [12]. It can be noticed that In-Sn-Zn eutectic alloy investigated in this work has a considerably higher melting temperature than the ternary $\mathrm{Bi}-\mathrm{In}-\mathrm{Sn}$ eutectic alloys. However, latent heat of melting for the $\mathrm{In}-\mathrm{Sn}-\mathrm{Zn}$ eutectic alloy determined in this work $\left(28.3 \mathrm{Jg}^{-1}\right)$ is comparable with those of $\mathrm{Bi}-\mathrm{In}-\mathrm{Sn}$ eutectic alloys [12]. 


\section{Thermal conductivity determination}

The characteristic of PCMs is that they store and release thermal energy in the form of latent heat when they change between their solid and liquid states. Hence, for the phase change to take place, the heat must flow into or out of the PCM. Therefore, the efficiency of the heat transfer during the phase change directly depends on the thermal conductivity of the PCM. It is known that metallic PCMs generally have very high thermal conductivities, which are much higher than thermal conductivities of other types of nonmetallic PCMs such as paraffin, fatty acids or salt hydrates [10]. This is undoubtedly their main advantage over the other types of PCMs. Thus, accurate data on the PCM thermal conductivity is of significant importance.

In this study, the thermal conductivity of the investigated In-Sn-Zn eutectic alloy was determined by using the xenon-flash technique [22].

Xenon-flash technique is based on direct measurement of the thermal diffusivity $(\alpha)$ of a disc-shaped specimen that is uniformly irradiated over its front surface with a very short pulse of energy coming from the flash lamp.

The determination of thermal diffusivity is based on the following equation proposed by Parker et al. [22]:

$$
\alpha=\frac{1.37 L^{2}}{\pi^{2} t_{1 / 2}}=0.1388 \frac{L^{2}}{t_{1 / 2}}
$$

where $L$ represents the thickness of the sample and $t_{1 / 2}$ is the half-rise time, defined as time interval required for the rear surface temperature to reach half of the maximal temperature increase.

Specific heat capacity of the investigated In-Sn-Zn eutectic alloy was calculated using optimized thermodynamic parameters from the literature [2].

Based on the measured thermal diffusivity, and the calculated specific heat capacity, the thermal conductivity of the investigated sample was determined using the following equation $[16,22]$ :

$$
\lambda=\alpha \cdot \rho \cdot C p
$$

where $\lambda$ is thermal conductivity $\left(\mathrm{Wm}^{-1} \mathrm{~K}^{-1}\right), \alpha$ is thermal diffusivity $\left(\mathrm{m}^{2} \mathrm{~s}^{-1}\right), \rho$ is density $\left(\mathrm{kgm}^{-3}\right)$, and $C \mathrm{p}$ is specific heat capacity $\left(\mathrm{Jg}^{-1} \mathrm{~K}^{-1}\right)$.

The alloy density $(\rho)$ at $25{ }^{\circ} \mathrm{C}$ was determined by using the Archimedes method [23].

The obtained values of thermal diffusivity, density, specific heat capacity, and thermal conductivity for the $\mathrm{In}-\mathrm{Sn}-\mathrm{Zn}$ eutectic alloy investigated at $25{ }^{\circ} \mathrm{C}$ are summarized in Table 3 . The total standard uncertainty ( 0.68 level of confidence) for the thermal conductivity is estimated to be $\pm 8 \%$ [23]. 
Table 3. Specific heat capacity, density, thermal diffusivity, and thermal conductivity of the investigated In-Sn-Zn eutectic alloy at $25^{\circ} \mathrm{C}$

\begin{tabular}{|c|c|c|c|c|}
\hline Alloy (at.\%) & $\begin{array}{c}\text { Specific } \\
\text { heat } \\
\text { capacity, } \\
\begin{array}{c}\mathrm{Cp} \\
\left(\mathrm{Jg}^{-1} \mathrm{~K}^{-1}\right)\end{array}\end{array}$ & $\begin{array}{c}\text { Density, } \rho \\
\left(\mathrm{gcm}^{-3}\right)\end{array}$ & $\begin{array}{c}\text { Thermal } \\
\text { diffusivity, } \\
\alpha \\
\left(\mathrm{mm}^{2} \mathrm{~s}^{-1}\right)\end{array}$ & $\begin{array}{c}\text { Thermal } \\
\text { conductivity, } \lambda \\
\left(\mathrm{Wm}^{-1} \mathrm{~K}^{-1}\right)\end{array}$ \\
\hline 52.7In-44.9Sn-2.4Zn & 0.233 & 7.236 & 25.010 & $42.2 \pm 3.4$ \\
\hline
\end{tabular}

The determined thermal conductivity of the In-Sn-Zn eutectic alloy at $25{ }^{\circ} \mathrm{C}$ $\left(42.2 \pm 3.4 \mathrm{Wm}^{-1} \mathrm{~K}^{-1}\right)$ is significantly lower than thermal conductivities of pure constitutive metals $\operatorname{In}\left(83.7 \mathrm{Wm}^{-1} \mathrm{~K}^{-1}\right)$, Sn $\left(62.8 \mathrm{Wm}^{-1} \mathrm{~K}^{-1}\right)$ and $\mathrm{Zn}\left(113.0 \mathrm{Wm}^{-1} \mathrm{~K}^{-1}\right)$ [13] as well as that of $\mathrm{Sn}-\mathrm{Zn}$ eutectic alloy $\left(61 \mathrm{Wm}^{-1} \mathrm{~K}^{-1}\right)$ [9]. However, it is higher than reported thermal conductivities of In-Sn solid eutectic alloy $\left(34 \mathrm{Wm}^{-1} \mathrm{~K}^{-1}\right)$ [24] and In-Sn liquid eutectic alloy at $250{ }^{\circ} \mathrm{C}\left(28.8 \mathrm{Wm}^{-1} \mathrm{~K}^{-1}\right)$ [25]. In a recent study [26], the thermal conductivity of the low-melting $\mathrm{Bi}-\mathrm{Sn}-\mathrm{Zn}$ eutectic alloy at room temperature has been measured under similar experimental conditions. The reported value of $22.9 \pm 1.9 \mathrm{Wm}^{-1} \mathrm{~K}^{-1}$ is considerably lower than the thermal conductivity of the In-Sn-Zn eutectic alloy obtained in the present research.

\section{Conclusion}

Low-melting alloys represent a new kind of PCMs that have been extensively studied. However, for many low-melting alloys, there is still a lack of reliable thermophysical data in the literature. As a contribution to fully understand thermophysical properties of In-based low melting alloys as PCMs candidates, the In$\mathrm{Sn}-\mathrm{Zn}$ eutectic alloy was investigated in this study. Important thermal properties such as melting temperature, latent heat of melting, thermal diffusivity, specific heat capacity and thermal conductivity of the $\mathrm{In}-\mathrm{Sn}-\mathrm{Zn}$ eutectic alloy were examined. The composition of the investigated eutectic alloy was chosen using the thermodynamically assessed In-Sn-Zn phase diagram. The thermodynamic analysis was used for the calculation of theoretical melting temperature, latent heat of melting and specific heat capacity. Using DSC measurements, the corresponding melting temperature and latent heat of melting of the $\mathrm{In}-\mathrm{Sn}-\mathrm{Zn}$ eutectic alloy were experimentally determined. The measured melting temperature is $106.5 \pm 0.1{ }^{\circ} \mathrm{C}$, which is in a close agreement with the calculated value of $106^{\circ} \mathrm{C}$. The latent heat of melting determined by DSC measurements is $28.3 \pm 0.1 \mathrm{Jg}^{-1}$, which is somewhat higher than the thermodynamically calculated value $\left(21.5 \mathrm{Jg}^{-1}\right)$. Based on the measured thermal diffusivity and calculated specific heat capacity value, the thermal conductivity of the investigated alloy at $25{ }^{\circ} \mathrm{C}$ was found to be $42.2 \pm 3.4 \mathrm{Wm}^{-1} \mathrm{~K}^{-1}$. 


\section{Acknowledgment}

The authors gratefully acknowledge the support of the Ministry of Education, Science and Technological Development of the Republic of Serbia, project No. OI172037.

\section{References}

[1] A. Debski, B. Onderka, W. Gasior, T. Gancarz: Arch. Metall. Mater., 62 (2017) 1945-1955.

[2] Y. Cui, X.J. Liu, I. Ohnuma, R. Kainuma, H. Ohtani, K. Ishida: J. Alloy Compd., 320 (2001) 234-241.

[3] M. McCormack, S. Jin, H. S. Chen, D. A. Machusak: J. Electron. Mater., 23 (1994) 687-690.

[4] J.M. Fiorani, C. Naguet, J. Hertz, A. Bourkba, L. Bouirden: Z.Metallkde., 88 (1997) 711-716.

[5] Y. Xie, H. Schicketanz, A. Mikula: Ber. Bunssenges. Phys. Chem., 102 (1998) 1334-1338.

[6] X.H. Yang, S.C. Tan, J. Liu: Int J Heat Mass Transf., 100 (2016) 899-907.

[7] X.H. Yang, S.C. Tan, Y.J. Ding, L. Wang, J. Liu, Y.X. Zhou, Int. Commun. Heat Mass., 87 (2017) 118-24.

[8] A.S. Fleischer, Thermal energy storage using phase change materials: fundamentals and applications. New York: Springer; 2015.

[9] H. Ge, H. Li, S. Mei, J. Liu: Renew Sustain Energy Rev., 21 (2013) 331-346.

[10] J. Rodriguez-Aseguinolaza, P. Blanco-Rodriguez, E. Risueno, M.J. Tello, S. Doppiu. J Therm Anal Calorim., 117 (2014) 93-99.

[11] I. Manasijević, Lj. Balanović, T. Holjevac Grgurić, D. Minić, M. Gorgievski: J Therm Anal Calorim., 136 (2019) 643-649.

[12] I. Manasijević, Lj. Balanović, T. Holjevac Grgurić, D. Minić, M. Gorgievski: Mater. Res.-Ibero-Am J., 21 (2018) e20180501.

[13] ASM Handbook Volume 2: Properties and Selection: Nonferrous Alloys and Special-Purpose Materials, (Materials Park, OH, ASM International, 1990). ISBN: 978-0-87170-378

[14] J.K. Wu, K.L. Lin, B. Salam, Journal of Electronic Materials, 38 (2009) $227-$ 230.

[15] C. Morando, O. Fornaro, O. Garbellini, H. Palacio: J Mater Sci: Mater Electron., 25(8) (2014) 3440-3447.

[16] D. Manasijević, Ž. Radović, N. Štrbac, Lj. Balanović, U. Stamenković, M. Gorgievski, M. Premović, T. Holjevac Grgurić, N. Tadić: Mater Test, 60 (12) (2018) 1175-1178.

[17] H.L. Lukas, S.G. Fries, B. Sundman: Computational thermodynamics: the calphad method. Cambridge: Cambridge University Press; 2007.

[18] B. Sundman: J. Min. Metall. Sect. B-Metall. 53(3) B (2017) 173-177.

[19] A. Kroupa, A.T. Dinsdale, A. Watson, J. Vrestal, J. Vízdal, A. Zemanova: JOM, 59 (7) (2007) 20-25.

[20] W. Cao, S.L. Chen, F. Zhang, K. Wu, Y. Yang, Y.A. Chang, R. Schmid-Fetzer, W.A. Oates: Calphad, 33 (2009) 328-342.

[21] W.J. Boettinger, U.R. Kattner, K.W. Moon, J.H. Perepezko: DTA and heat flux DSC measurements of alloys melting and freezing. In: Zhao JC, editor. Methods for phase diagram determination. Oxford: Elsevier; 2007. p. 152-222. 
[22] W.J. Parker, R.J. Jenkins, C.P. Butler, G.L. Abbott: J Appl Phys, 32 (9) (1961) 1679-1684.

[23] L. Huang, S. Liu, Y. Du, C. Zhang: Calphad, 62 (2018) 99-108.

[24] Indium Corporation, Denotes Materials that Indium Corporation can provide, https://www.indium.com/thermal-management/thermal-k-list/. Accessed 02 March 2019.

[25] S. Stankus, I.V. Savchenko, A.Sh. Agazhanov: Int. J. Thermophys, 33 (2012) 774-782.

[26] I. Manasijević, Lj. Balanović, D. Minić, M. Gorgievski, U. Stamenković: Kovove Mater., 57 (2019) 267-273.

\section{(c) $\underset{\text { EY }}{(i)}$ Creative Commons License}

This work is licensed under a Creative Commons Attribution 4.0 International License. 